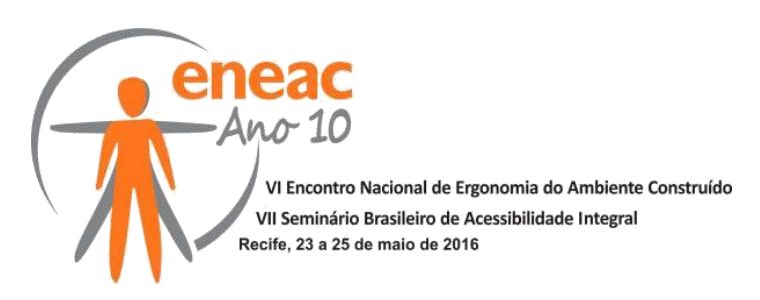

\title{
PESQUISA DE SATISFAÇÃO DO TRANSPORTE PÚBLICO COLETIVO PELO USUÁRIO COM DEFICIÊNCIA
}

\author{
SILVEIRA, Carolina Stolf (1); \\ HAGEMANN, Luiz Fernando (2); \\ MÁXIMO, Amanda Carolina (3). \\ (1) Fundação Instituto de Pesquisa e Planejamento para o Desenvolvimento Sustentável \\ de Joinville - IPPUJ, Mestre em Arquitetura e Urbanismo \\ e-mail: carolina.silveira@joinville.sc.gov.br \\ (2) IPPUJ, Arquiteto e Urbanista \\ e-mail: luiz.hagemann@joinville.sc.gov.br \\ (3) IPPUJ, Mestre em Arquitetura e Urbanismo \\ e-mail: amanda.ippuj@joinville.sc.gov.br
}

\begin{abstract}
RESUMO
A acessibilidade ao sistema de transporte público coletivo é garantida pela Lei Federal 10.098/2000, atualizada pela Lei Brasileira de Inclusão (13.146/ 2015), promovendo o direito de ir e vir de pessoas com deficiência através do transporte coletivo. Ava liar o nível de satisfação do sistema por esses usuários faz-se necessário para medir os fatores de qualidade do serviço, sendo o mais importante deles, o de acessibilidade o qual permite que o usuário possa ser incluído no sistema. Este resumo apresenta uma proposta de pesquisa de satisfação do sistema de transporte público coletivo por ônibus pelo usuário com deficiência.
\end{abstract}

Palavras chave: pesquisa de satisfação; transporte público coletivo; acessibilidade.

\begin{abstract}
The accessibility of public transportation system is guaranteed by Federal Law 10,098 / 2000, updated by the Brazilian Law Inclusion (13,146 / 2015), promoting the right of movement of people with disabilities. Evaluate system level of satisfaction for these users it is necessary to measure the quality of service factors, the most important of them, the accessibility which allows the user to be included in the system. This summary presents a proposal for a satisfaction survey of the public transportation system by bus user with disabilities.
\end{abstract}

Keywords: accessibility; public transportation; satisfaction survey

\section{INTRODUÇÃO}

Buscando avaliar anualmente o serviço do sistema de transporte público coletivo por ônibus de Joinville/SC, a Fundação Instituto de Pesquisa e Planejamento para o Desenvolvimento Sustentável de Joinville - IPPUJ, através de cooperação técnica com o WRI Brasil Cidades Sustentáveis, desde 2014 aplica pesquisa de satisfação com o usuário do transporte público coletivo por ônibus.

A pesquisa, chamada de "Qualiônibus", foi desenvolvida pela WRI Brasil Cidades Sustentáveis (2014) e tem por objetivo principal avaliar detalhadamente a opinião dos 


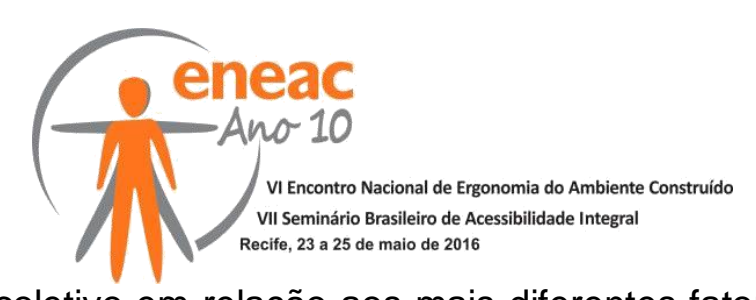

usuários do transporte coletivo em relação aos mais diferentes fatores de qualidade. Como objetivos específicos busca: padronizar as pesquisas de satisfação com um questionário completo e flexível, que permita entender a satisfação e necessidades dos clientes em relação a cada fator da qualidade e medir o impacto de intervenções ou melhorias; obter informações quantitativas para apoiar o processo de tomada de decisões; identificar desafios e oportunidades comuns às cidades para discutir soluções integradas; verificar o impacto decorrente da implantação de novos sistemas de transporte coletivo; e contribuir para a gestão da qualidade do transporte coletivo.

Estruturada por módulos a pesquisa ocorre através de entrevista com o usuário embarcado no ônibus e engloba os seguintes fatores de qualidade: acesso ao transporte; disponibilidade; rapidez; confiabilidade; facilidade em fazer transferências; conforto; atenção ao cliente; informação ao cliente; segurança; segurança em relação a acidentes; exposição ao ruído e poluição; facilidade para pagar; e gasto.

Considerando a ausência do fator acessibilidade e d a necessidade de avaliá-lo não apenas no sistema de transporte público coletivo por ônibus convencional, mas também no sistema de transporte coletivo por micro-ônibus porta-a-porta (para atender pessoas com deficiência físico motora ou múltipla que tenham grandes dificuldades de locomoção, buscando-a na origem e deixando-a no destino desejado), elaborou-se módulo específico e adequou-se a pesquisa padrão do WRI Cidades Sustentáveis (2014) para uma específica ao sistema porta-a-porta, tendo em vista que esse não engloba estações/terminais ou abrigos de ônibus, além de considerar as especificidades do usuário com deficiência.

A seguir apresenta-se módulo específico elaborado para entrevistar pessoas com deficiência usuárias do sistema de transporte coletivo convencional e em seguida, a pesquisa adequada para atender os usuários do sistema porta-a-porta.

\section{MÓDULO DE AVALIAÇÃO DA ACESSIBILIDADE}

Além da pessoa com deficiência responder aos demais módulos da pesquisa Qualiônibus, o módulo proposto de acessibilidade também deve ser questionado na entrevista embarcada.

A primeira questão pergunta se a pessoa possui deficiência e qual (físico-motora, visual, auditiva, intelectual, múltipla, psicossocial) ou se costuma acompanhar alguma pessoa com deficiência.

A segunda questão aborda o nível de satisfação do usuário em relação a: informação sonora; pisos táteis; informação tátil (mapas táteis, em Braille); existência de funcionários para dar informação e auxiliar pessoas com deficiência (como intérprete de LIBRAS, por exemplo); preparação dos funcionários para atender pessoas com deficiência; acessibilidade até os pontos de embarque; acessibilidade dos abrigos de ônibus e dos terminais/estações; acessibilidade dos ônibus; facilidade para acessar e usar o serviço de ônibus por pessoas com deficiência.

A terceira questiona quais os principais problemas que o usuário ou seu acompanhante enfrentam para usar o sistema de transporte, podendo optar por mais de uma alternativa, sendo essas: "falta de funcionários capacitados para dar informações em LIBRAS", "ausência de pisos táteis", "ausência de informação sonora e táteis (relevo ou em Braille)"; "ausência ou poucos funcionários para auxiliar"; "dificuldade para acessar os pontos de ônibus e terminais/estações"; "a frota não é acessível"; e "outro", podendo o entrevistado especificar o problema enfrentado. 


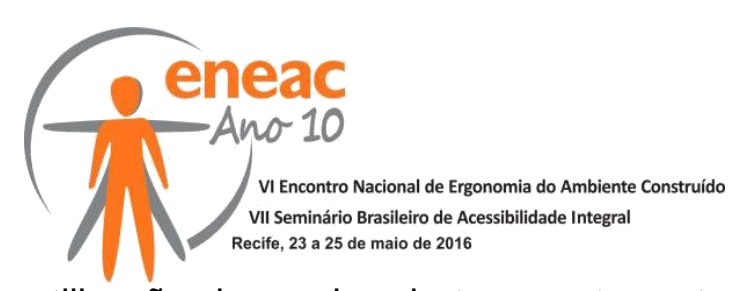

Buscando saber sobre a utilização do serviço de transporte porta-a-porta a última questão pergunta se o usuário ou seu acompanhante costuma utilizar esse serviço, podendo responder: nunca; raramente; com frequência; ou desconheço o sistema.

\section{PESQUISA DE SATISFAÇÃO DO TRANSPORTE PORTA-A-PORT A}

A pesquisa para o usuário do sistema porta-a-porta baseou-se no questionário original desenvolvido pelo WRI Brasil Cidades Sustentáveis (2014), fazendo-se adequações para o sistema e seus usuários.

O questionário inicia com um módulo básico, questionando o número de vezes que o usuário utiliza o sistema na semana, finalidade do uso, tempo gasto e se poderia ter realizado a viagem através de outro modo de transporte. O módulo básico segue com perguntas de satisfação geral do sistema porta-a-porta, em uma escala de 1 (muito insatisfeito) a 5 (muito satisfeito) quanto à: disponibilidade; rapidez; confiabilidade; conforto dos veículos: iluminação, limpeza, quantidade de pessoas, assentos; atendimento ao cliente: respeito, cordialidade e preparo dos motoristas, funcionários e central de atendimento; segurança em relação a acidentes de trânsito; exposição a ruído e poluição gerada pelos ônibus; e satisfação geral com o transporte porta-a-porta. Este módulo finaliza com perguntas de concordância: "utilizar o transpor te porta-a-porta contribui para a minha qualidade de vida"; "posso confiar no transporte porta-a-porta para meus deslocamentos"; "o transporte porta-aporta enfrenta muito congestionamento"; "frequentemente enfrento situações em que os ônibus estão excessivamente lotados"; "os motoristas conduzem os ônibus de forma segura"; e "recomendaria o sistema de transporte porta-a-porta".

O questionário segue com os módulos detalhados, sendo os mais relevantes: acesso ao transporte porta-a-porta (facilidade de embarcar e desembarcar dos ônibus); percepção sobre o ônibus (é fácil usar o sistema de transporte; posso confiar que o transporte portaa-porta chega ao destino sem interrupções de viagem ou quebras; o sistema de transporte porta-a-porta me passa uma boa imagem); e evolução (no último ano, o serviço de transporte porta-a-porta em uma escala de 1 - piorou muito a 5 - melhorou muito).

\section{CONSIDERAÇÕES FINAIS}

Pesquisas de satisfação aos usuários do transporte público coletivo devem considerar todos, independente de suas condições físicas ou sensoriais. Para isso, algumas peculiaridades devem ser levadas em consideração, como por exemplo, orientação e informação acessível, como pisos e mapas táteis, em Braille, LIBRAS e informação sonora.

Na existência de um sistema de transporte coletivo porta-a-porta, estes usuários também devem ser entrevistados, possibilitando a identificação dos problemas ou problemas potenciais, buscando solucioná-los ou evitá-lo, aprimorando o sistema e garantindo o direito de ir e vir com segurança e dignidade.

\section{REFERÊNCIAS BIBLIOGRÁFICAS}

BRASIL. Lei Federal n. 10.098, de 19 de dezembro de 2000. Estabelece normas gerais e critérios básicos para a promoção da acessibilidade das pessoas portadoras de deficiência ou com mobilidade reduzida, e dá outras providências. Brasília, 2000.

BRASIL. Lei Federal n. 13.146, de 6 de julho de 2015. Institui a Lei Brasileira de Inclusão da Pessoa com Deficiência (Estatuto da Pessoa com Deficiência ).

WRI Brasil Cidades Sustentáveis. Qualiônibus - Pesquisa de Satisfação. 2014. Disponível em: http://wricidades.org/node/47381. Acessado em janeiro de 2016. 